\title{
Long-term effects of sulfur mustard on civilians' mental health 20 years after exposure (The Sardasht-Iran Cohort Study)
}

\author{
Rasoul Roshan ${ }^{1,2}$, Parvin Rahnama ${ }^{3}$, Zeinab Ghazanfari ${ }^{4,5}$, Ali Montazeri ${ }^{6}$, Mohammad Reza Soroush $^{7}$, \\ Mohammad Mehdi Naghizadeh ${ }^{8}$, Mahdiyeh Melyani ${ }^{9}$, Azadeh Tavoli ${ }^{9}$ and Tooba Ghazanfari ${ }^{1}, 10^{*}$
}

\begin{abstract}
Background: Sulfur mustard (SM) is an alkylating agent that induces short and long term toxicity on various organs. The aim of this study was to assess the long-term psychological symptoms among samples of exposed to sulfur mustard gas compared with unexposed civilians 20 years after exposure.

Methods: This historical cohort study was conducted on 495 civilians of Sardasht and Rabat in two age matched groups, including 367 sulfur mustard exposed participants from Sardasht and 128 unexposed subjects from Rabat. Psychological symptoms was assessed using the Symptom Check List-90 Revised (SCL-90-R) including measures of somatization, obsessive-compulsive, interpersonal sensitivity, depression, anxiety, hostility, phobic anxiety, paranoid ideation, and psychoticism providing three global distress indices namely: Global Severity Index (GSI), Positive Symptom Total (PST) and Positive Symptom Distress Index (PSDI). Comparison was made between exposed and unexposed civilians.

Results: There were significant differences in somatization ( $P=0.002)$, obsessive-compulsive $(P=0.031)$, depression $(P=0.007)$, anxiety $(P=0.042)$, and hostility $(P=0.002)$, between the exposed and unexposed groups. In addition there were significant differences between two groups concerning the GSI $(P=0.045)$ and the PSDI $(P<0.001)$. The differences between two groups in other subscales were not significant.

Conclusions: The findings from this study showed that civilians who exposed to sulfur mustard gas were suffering from a number of psychological symptoms even 20 years after exposure. Providing mental health services and more resource allocation for this community are highly recommended.
\end{abstract}

\section{Background}

Sulfur Mustard [bis-(2-chloroethyl) sulfide; mustard gas] is a vesicant chemical agent that can produce significant morbidity [1]. This agent was been used during the IraqIran war between 1980 and 1988. Over 100,000 poorly protected soldiers suffered severe injuries as a result and roughly 45,000 soldiers continue to suffer long-lasting consequences of exposure [2]. Sardasht is a town in the north-west of Iran close to the Iraqi border. During the Iraqi war against Iran civilians of Sardasht were also exposed to mustard gas on June 28, 1987 [3].

\footnotetext{
* Correspondence: tghazanfari@yahoo.com

${ }^{1}$ Immunoregulation Research Center, Shahed University, Tehran, Iran

${ }^{10}$ Department of Immunology, Shahed University, Tehran, Iran

Full list of author information is available at the end of the article
}

Mustard gas can be absorbed through skin, respiratory system, genital tract, and ocular surface [2]. It affects many organs such as skin, eyes, lungs, gastrointestinal, endocrine and hematopoietic system [4]. Respiratory diseases are the major cause of long-term disability among these patients [2]. In addition, it has been also known as a DNA alkylating agent and classified as a known human carcinogen [5].

In a study on 34000 Iranians after exposure to mustard gas the most common complications were revealed in the lungs (42.5\%), eyes (39.3\%), and skin (24.5\%) [6]. However, the effects of sulfur mustard are not restricted to these known injuries. As such it is argued that exposure to sulfur mustard gas is a traumatic event that has long-lasting effects on mental health. Mental health is a basic and integrated component of health [7]. It is well

\section{() BioMed Central}


established that that there is a strong relationship between physical and mental health [8]. It is believed that the burdens of mental illnesses continue to rise worldwide and the most common mental health problems are depression and anxiety disorders [9].

Studies have reported that survivors who were exposed to both high-intensity warfare and chemical weapons were more prone to have lifetime post-traumatic stress disorder (PTSD), current PTSD, increased anxiety and depressive symptoms than those who exposed to highintensity warfare alone [10-13]. In turn PTSD was found to be associated with increased risk of somatic symptoms and medical illnesses. Even PTSD might elevate prevalence rates of depression, anxiety and substance abuse in trauma survivors [11]. For instance, a prospective study in a non-treatment seeking sample of Iraqi war veterans revealed that the PTSD severity was associated with changes in somatic health related functioning, and with increased use of health care services [12]. In addition, it has been found that regardless of the level of physical disability, depression symptom is more evident in chemical warfare victims than those exposed to nonchemical warfare [14]. Furthermore exposure to chemical weapons has been associated with a higher prevalence of depression and anxiety disorders compared to the exposure to war-related violence alone [10].

Exposure to chemical warfare is a severe traumatic event with long-lasting effects on mental health. Survivors of chemical warfare usually suffer from psychological disorders including depression, long-term mood disorder, anxiety, post-traumatic stress disorder, and sexual dysfunction [15]. Little information exists on the topic in Iran. Thus the Sardasht-Cohort Study was initiated in order to provide help and support for civilian victims. This paper reports on psychological symptoms of civilians after twenty years exposure.

\section{Methods}

\section{Study design and participants}

The Sardasht-Iran Cohort Study (SICS) was designed twenty years after sulfur mustard exposure. The design and methods of the study were explained in details elsewhere [16]. In summary participants in this study were recruited from Sardasht (exposed) and Rabat (unexposed) residents. Rabat residents were exposed to intensive conventional warfare but not to chemical weapons. The exposed group was selected from the male individuals of Sardasht exposed to sulfur mustard 20 years ago based on the documents in the medical records verified by the Medical Committee of the Foundation of Martyr and Veterans Affair. In the medical records, each victim has a medical file with a numeric code. The participants were selected by systematic random sampling method from the chemical victims' list. Since the ratio of sample size to records was 0.1 , each sample was selected from every 10 records. Having studied the medical records, chemical victims were categorized into two major subgroups based on the severity of the clinical problems at the time of exposure: 1) hospitalized: victims who had moderate to severe problems and were hospitalized in Iran or sent aboard for treatment, and 2) non-hospitalized: patients who had subclinical or mild problems and were treated for acute effects on an outpatient basis. The unexposed control group was enrolled from Rabat. These participants resembled the exposed group from all aspects except exposure to sulfur mustard. Rabat is a town located 15 kilometers away from Sardasht. Both towns have similar geographical situations. They have Kurdish populations with the same religion, culture, language, and nutritional habits. The control sample included males selected by systematic random sampling from the list of latest household statistics. They were matched with the exposed group by age. After a few field trips to Sardasht and Rabat, the research team made a complete list of addresses and phone numbers of selected individuals. Civilians were then contacted by phone, and invited for interview in order to collect data on psychological symptoms. A psychiatrist interviewed all participants in a private setting in a public care center. Each interview lasted for about 30-45 minutes. Participants were included if they were 20 to 60 years old. The minimum age of 20 years was chosen because this age includes individuals who were newborns at the time of exposure. The elderly persons over 60 also were excluded to avoid unintended results due to other health conditions. In addition participants with current treatment with systemic immunosuppressive drugs, history of systemic disease before exposure based on medical records, suffering from an acute infectious disease at the time of sampling, and those who had any types of known psychological disorders such as schizophrenia and bipolar abnormalities were excluded.

\section{Instrument}

The Symptom Check List 90 Revised (SCL-90-R) was used to collect data on psychological symptoms [17]. It includes 90 questions in 9 different psychological subscales: somatization, obsessive-compulsive, interpersonal sensitivity, depression, anxiety, hostility, phobic anxiety, paranoid ideation, and psychotic sulfur mustard. It also provides three global distress indices namely: Global Severity Index (GSI), Positive Symptom Total (PST) and Positive Symptom Distress Index (PSDI). The GSI is the average score of the 90 items of the questionnaire [18]. It is suggested to be the best single indicator of the current level of the disorder. There is a cut-off point for the GSI. An optimal cut-off point of 0.4 was considered based on the standardized test results for Iran [19]. The 
Positive Symptom Total (PST) is a count of all the items with non-zero responses and reveals the number of symptoms that the respondent reports experiencing. The Positive Symptom Distress Index (PSDI) is the sum of the values of the items receiving non-zero responses divided by the PST [17]. The psychometric properties of the Iranian version of SCL-90-R are well documented [20].

\section{Analysis}

Descriptive analyses were carried out to explore the data. Statistical procedures including chi square test and $t$ test were performed to compare exposed and unexposed civilians. Linear regression analysis was performed to examine the relationships between the scores of SCL-90-R and demographic parameters and GSI scores. A significance level equal to 0.05 or lower was adopted for all main analysis. The SPSS version 13 (SPSS Inc, Chicago IL) was used to analyze the data.

\section{Ethics}

Ministry of Health of Iran, Janbazan Organisation, and Shahed University approved the study. Informed consent was provided from all the participants after explaining the aim of the study to them.

\section{Results}

In all, 495 participants were studied (367 in exposed and 128 in control groups). There were no significant differences in terms of age, body mass index, marital status and employment status between the exposed and control groups (Table 1).

There were significant differences in somatization $(P=0.002)$, obsessive-compulsive $(P=0.031)$, depression $(\mathrm{P}=0.007)$, anxiety $(\mathrm{P}=0.042)$, and hostility $(\mathrm{P}=0.002)$ between two groups, but no significant differences were observed for other subscales. The results showed that there were also significant differences between two groups concerning the GSI $(\mathrm{P}=0.045)$ and the PSDI $(\mathrm{P}<0.001)$. The detailed results are shown in Table 1 . However, the influence of demographic factors on psychological health status was examined and the results are shown in Table 2. In most instances being old and being in exposed group were significant factors for lower psychological health status.

Table 1 Demographic characteristics and the SCL-90-R score of the study groups

\begin{tabular}{|c|c|c|c|}
\hline & Control $(n=128)$ & Exposed $(n=367)$ & $\mathbf{P}$ \\
\hline Age $($ Mean $\pm S D)$ & $42 \pm 10$ & $44 \pm 11$ & $0.262^{*}$ \\
\hline BMI (Mean \pm SD) & $25.8 \pm 4.0$ & $26.3 \pm 3.9$ & $0.293^{*}$ \\
\hline Marital status (number, \%) & & & $0.892^{* *}$ \\
\hline Single & $11(8.6)$ & $33(9.0)$ & \\
\hline Married & 117(91.4) & 334(91.) & \\
\hline Education (number, \%) & & & $<0.001^{* *}$ \\
\hline Primary and secondary school & $99(77.3)$ & 214(58.3) & \\
\hline High school and upper & $29(27.3)$ & 153(41.7) & \\
\hline Employment status (number, \%) & & & $0.237^{* *}$ \\
\hline Employed & 73(57) & $231(62.9)$ & \\
\hline Unemployed & $55(43.0)$ & $136(37.1)$ & \\
\hline Somatization (mean \pm SD) & $1.50(0.88)$ & $1.78(0.82)$ & $0.002^{*}$ \\
\hline Obsessive-compulsive (mean \pm SD) & $1.37(0.85)$ & $1.55(0.79)$ & $0.031^{*}$ \\
\hline Interpersonal sensitivity (mean \pm SD) & $1.08(0.76)$ & $1.17(0.75)$ & $0.246^{*}$ \\
\hline Depression (mean \pm SD) & $1.20(0.75)$ & $1.42(0.81)$ & $0.007^{*}$ \\
\hline Anxiety (mean $\pm S D)$ & $1.24(0.81)$ & $1.41(0.80)$ & $0.042^{*}$ \\
\hline Hostility (mean \pm SD) & $1.10(0.84)$ & $1.36(0.78)$ & $0.002^{*}$ \\
\hline Phobic anxiety (mean \pm SD) & $0.76(0.72)$ & $0.74(0.81)$ & $0.780^{*}$ \\
\hline Paranoid ideation (mean \pm SD) & $1.20(0.80)$ & $1.26(0.74)$ & $0.479^{*}$ \\
\hline Psychoticism (mean \pm SD) & $0.78(0.66)$ & $0.83(0.69)$ & $0.540^{*}$ \\
\hline Global severity index (GSI) $($ mean \pm SD) & $1.16(0.70)$ & $1.31(0.68)$ & $0.045^{*}$ \\
\hline Positive symptom total (PST) (Mean \pm SD) & $51.10(23.25)$ & $52.91(19.80)$ & $0.406^{*}$ \\
\hline Positive symptom distress index (PSDI) (mean \pm SD) & $1.94(0.46)$ & $2.14(0.48)$ & $<0.001^{*}$ \\
\hline
\end{tabular}

* Comparison with control group derived from t-test.

** Comparison with control group derived from chi square test. 
Table 2 The relationships between the scores of SCL-90-R and demographic parameters and GSI scores

\begin{tabular}{|c|c|c|c|c|c|c|c|}
\hline & & Age (years) & BMI $\left(\mathrm{kg} / \mathrm{m}^{2}\right)$ & Marital & Education & Occupation & Exposure \\
\hline \multirow[t]{2}{*}{ Somatization } & Beta & -0.002 & 0.008 & 0.248 & 0.050 & 0.065 & 0.313 \\
\hline & P-value & 0.587 & 0.416 & 0.141 & 0.558 & 0.458 & 0.002 \\
\hline \multirow[t]{2}{*}{ Obsessive-compulsive } & Beta & -0.003 & 0.001 & 0.134 & 0.060 & 0.086 & 0.225 \\
\hline & P-value & 0.493 & 0.926 & 0.411 & 0.469 & 0.316 & 0.019 \\
\hline \multirow[t]{2}{*}{ Interpersonal sensitivity } & Beta & -0.012 & -0.002 & 0.128 & 0.058 & 0.108 & 0.125 \\
\hline & P-value & 0.004 & 0.857 & 0.397 & 0.450 & 0.173 & 0.161 \\
\hline \multirow[t]{2}{*}{ Depression } & Beta & -0.009 & 0.003 & 0.170 & 0.113 & -0.063 & 0.304 \\
\hline & P-value & 0.046 & 0.794 & 0.295 & 0.169 & 0.456 & 0.002 \\
\hline \multirow[t]{2}{*}{ Anxiety } & Beta & -0.012 & 0.006 & 0.245 & 0.096 & 0.112 & 0.194 \\
\hline & P-value & 0.005 & 0.525 & 0.128 & 0.238 & 0.182 & 0.040 \\
\hline \multirow[t]{2}{*}{ Hostility } & Beta & -0.009 & 0.007 & 0.086 & 0.102 & 0.050 & 0.223 \\
\hline & P-value & 0.049 & 0.491 & 0.598 & 0.220 & 0.556 & 0.020 \\
\hline \multirow[t]{2}{*}{ Phobic anxiety } & Beta & -0.010 & -0.002 & -0.055 & -0.015 & 0.158 & -0.020 \\
\hline & P-value & 0.016 & 0.843 & 0.733 & 0.856 & 0.061 & 0.830 \\
\hline \multirow[t]{2}{*}{ Paranoid ideation } & Beta & -0.014 & 0.011 & -0.064 & 0.086 & 0.338 & -0.002 \\
\hline & P-value & $<0.001$ & 0.212 & 0.665 & 0.251 & $<0.001$ & 0.978 \\
\hline \multirow[t]{2}{*}{ Psychoticism } & Beta & -0.011 & -0.003 & -0.086 & 0.036 & 0.101 & 0.069 \\
\hline & P-value & 0.004 & 0.696 & 0.538 & 0.608 & 0.164 & 0.400 \\
\hline \multirow[t]{2}{*}{ GSI } & Beta & -0.009 & 0.003 & 0.096 & 0.065 & 0.090 & 0.169 \\
\hline & P-value & 0.021 & 0.730 & 0.491 & 0.354 & 0.219 & 0.039 \\
\hline \multirow[t]{2}{*}{ PST } & Beta & -0.335 & 0.132 & 2.024 & 1.359 & 2.815 & 2.669 \\
\hline & P-value & 0.002 & 0.602 & 0.628 & 0.520 & 0.197 & 0.276 \\
\hline \multirow[t]{2}{*}{ PSDI } & Beta & -0.002 & 0.001 & 0.107 & 0.068 & -0.018 & 0.233 \\
\hline & P-value & 0.417 & 0.996 & 0.272 & 0.167 & 0.720 & $<0.001$ \\
\hline
\end{tabular}

Beta: Regression coefficient (Married $=1)($ High school and upper $=1)($ Unemployed $=1)($ Exposed $=1)$.

The results showed that a larger proportion of cases had psychological symptoms than controls $(92.7 \%$ in exposed vs. $84.5 \%$ in control group; $\mathrm{P}=0.006$ ) (Table 3 ). In addition when we analyzed the data based on severity of symptoms, the results indicated that there were no significant score differences between hospitalized and non-hospitalized patients (Table 4).

\section{Discussion}

This study aimed to assess psychological distress among people who exposed to mustard gas in Sardash, Iran. The findings showed that the exposed civilians had a higher degree of psychological symptoms as compared to the controls. The global severity index (GSI) in the exposed group was significantly higher than the control group; mean values (SD) were $1.31(0.68), 1.16(0.70)$, respectively $(\mathrm{P}=0.04)$. No surprisingly a recent publication from Iran also revealed that the mean GSI in survivors of chemical warfare with ophthalmologic complications was higher than standardized cut-off point for Iranian community [21]. Similarly, a Danish study among subjects who had been deployed in the Persian Gulf reported that the mean values of the GSI in Gulf War veterans were higher than controls; the mean values $(\mathrm{SD})$ were $0.20(0.26)$ and $0.12(0.17)$, respectively $(\mathrm{P}<0.001)$ [22]. It has been suggested that the increased psychological distress in Danish

Table 3 Psychological disorders according to the GSI index cut-off values in exposed and controls

\begin{tabular}{llll}
\hline & Control $(\mathbf{n = 1 2 8})$ & Exposed $(\mathbf{n}=\mathbf{3 9 7})$ \\
\hline Psychological status & No. $(\%)$ & No. $(\%)$ & \\
Normal (global severity index $<\mathbf{0 . 4 )}$ & & $27(7.3)$ \\
Probable case (global severity index $\geq \mathbf{0 . 4})$ & $20(15.5)$ & $340(92.7)$ \\
\hline
\end{tabular}

\footnotetext{
* Comparison with control group derived from chi square test.
} 
Table 4 Severity of the mental health disturbances among the study participants by Severity of the exposure

\begin{tabular}{|c|c|c|c|c|c|c|}
\hline & Control & Exposed $(n=367)$ & & & & \\
\hline & $(n=128)$ & Non-hospitalized $(n=192)$ & & Hospitalized $(n=162)$ & & \\
\hline & Mean (SD) & Mean (SD) & $\mathrm{P}^{*}$ & Mean (SD) & $\mathbf{P}^{*}$ & $\mathrm{P}^{* * *}$ \\
\hline Somatization & $1.50(0.88)$ & $1.78(0.83)$ & 0.014 & $1.78(0.82)$ & 0.016 & 0.998 \\
\hline Obsessive-compulsive & $1.37(0.85)$ & $1.54(0.81)$ & 0.155 & $1.56(0.77)$ & 0.109 & 0.963 \\
\hline Interpersonal sensitivity & $1.08(0.76)$ & $1.19(0.75)$ & 0.428 & $1.15(0.75)$ & 0.707 & 0.891 \\
\hline Depression & $1.20(0.75)$ & $1.40(0.80)$ & 0.073 & $1.45(0.82)$ & 0.024 & 0.840 \\
\hline Anxiety & $1.24(0.81)$ & $1.41(0.78)$ & 0.184 & $1.42(0.81)$ & 0.146 & 0.978 \\
\hline Hostility & $1.10(0.84)$ & $1.37(0.79)$ & 0.013 & $1.36(0.78)$ & 0.019 & 0.999 \\
\hline Phobic anxiety & $0.76(0.72)$ & $0.75(0.81)$ & 0.999 & $0.71(0.82)$ & 0.883 & 0.883 \\
\hline Paranoid ideation & $1.20(0.80)$ & $1.31(0.75)$ & 0.431 & $1.20(0.74)$ & 0.998 & 0.339 \\
\hline Psychoticism & $0.78(0.66)$ & $0.82(0.69)$ & 0.891 & $0.84(0.70)$ & 0.795 & 0.972 \\
\hline Global severity index (GSI) & $1.16(0.70)$ & $1.31(0.68)$ & 0.160 & $1.31(0.68)$ & 0.188 & 1.000 \\
\hline Positive symptom total (PST) & $51.10(23.25)$ & $53.05(19.75)$ & 0.695 & $52.73(19.93)$ & 0.788 & 0.989 \\
\hline Positive symptom distress index (PSDI) & $1.94(0.46)$ & $2.14(0.50)$ & 0.001 & $2.15(0.46)$ & 0.001 & 0.986 \\
\hline
\end{tabular}

* Comparison with control group derived from t-test.

** Comparison between hospitalized and non-hospitalized group derived from t-test.

veterans was due to mentally distressing environment and not the neurotoxic exposure. However, lower scores in the Danish study compared with the present study might be due to several reasons. For instance, perhaps the Danish authorities implemented some effective clinical and social interventions for the Golf War veterans while we did not. Other reasons might include the fact that the Danish veterans were healthier than the Iranian civilians. There is evidence that of 34000 Iranians examined 13-20 years after exposure to SM, it was found that a considerable percentage are suffering from long term complications from exposure involving the lungs (42.5\%), eyes (39\%), and skin $(24.5 \%)$ [6].

The results of this study showed that there were significant differences in hostility, anxiety, obsessive-compulsive, somatization and depression among the exposed and the control groups. The Danish study showed that, six dimensions on the SCL-90 including obsessive-compulsive, depression, interpersonal sensitivity, anxiety and hostility were associated with being a Gulf War veteran [22]. Interestingly both studies (the Danish and our study) did not find any significant differences in phobic, paranoid, and psychoticism among the cases and the controls. Perhaps these findings suggest that such psychological disorders are not related to neurotoxi exposure.

The development of psychiatric disorders among chemical victims is often due to severe sequelae. Studies have shown that there is strong association between physical illness with subsequent disability and psychiatric disorders in chemical warfare survivors [23-25]. Thus, one might argue that the higher rate of mental health problems in chemical warfare patients might be due to the higher rate of morbidities among this community
[26]. There is evidence that exposure to mustard gas can cause both early toxic and long-term adverse health effects [27]. In addition it seems that exposure to war; adverse physical health consequences and fear of the future represent an additive effect for involved and persistent mental health [10]. However, the Sardasht-Iran Cohort Study was designed to compare those who were afflicted by sulfur mustard exposure to those who were not. Intensive conventional warfare took place in both Sardasht and Rabat, but the Sardasht cohort was comprised of victims, while the control group from Rabat was not necessarily victims (i.e., physically wounded by the conflict). Therefore, chemical burns produce more of the persistent psychological symptoms than the bullet wounds of conventional warfare.

The impact of demographic factors (other than age and being in the exposed group) on psychological health status was very little (see Table 2). Such observation indicates that the most important factor for developing psychological problems is exposure to sulfur mustard gas. Every effort to destroy such weapons seems very relevant to public's health worldwide.

Finally, while logically the more severe exposure seems to be accompanied with more psychological problems, our study did not show that the severity of exposure affects the severity of psychological disturbances. It seems that the other confounding factors involved in this regard and needs further investigations.

\section{Limitations}

This study had some limitations. Firstly, as noted, because of similar religion, culture, language and nutritional habits, Rabat civilians were considered as control 
group to compare to Sardasht exposed individuals. Since Rabat civilians themselves probably suffered from this incident and war as a big trauma indirectly so the results of this study cannot be considered as a comparison between sulfur mustard exposed and a normal population. Secondly, this study did not differentiate between the psychological symptoms induced by sulfur mustard itself and the symptoms induced by the horror and the fears in the city from heavy explosions. Thus the results should be interpreted with some cautions.

\section{Conclusion}

This study found that civilians exposed to sulfur mustard gas were suffering from a number of psychological symptoms even 20 years after exposure. It seems that providing mental health services and more resources allocation for this community is warranted in addition to efforts to manage physical symptoms of chemical agent exposure.

\section{Competing interests}

The authors declare that they have no competing interests.

\section{Authors' contributions}

RR participated in study design, questionnaire preparation and manuscript writing; PR participated in manuscript preparation; ZGH collected data and participated in manuscript preparation; AM contributed to the analysis, critically evaluated the paper, and provided the final draft; MRS participated in data collection; MMN performed the statistical analysis and interpreted data; MM and AT drafted the manuscript; TGH designed and coordinated the study. All authors read and approved the final manuscript.

\section{Acknowledgements}

The work was supported by Iranian Foundation of Martyr and Veterans Affairs and Ministry of Health and Medical Education, Shahed University and Janbazan Medical and Engineering Research Center (JMERC). We would like to thank all the participants who took part in the study and dedicated their time and different specimens very kindly.

\section{Author details}

${ }^{1}$ Immunoregulation Research Center, Shahed University, Tehran, Iran. ${ }^{2}$ Department of Psychology, Shahed University, Tehran, Iran. ${ }^{3}$ Department of Midwifery, Shahed University, Tehran, Iran. ${ }^{4}$ Psycho-Social Injuries Research Center, Ilam University of Medical Sciences, Ilam, Iran. ${ }^{5}$ Department of Public Health, Ilam University of Medical Sciences, Ilam, Iran. ${ }^{6}$ Mental Health Research Group, Health Metrics Research Center, Iranian Institute for Health

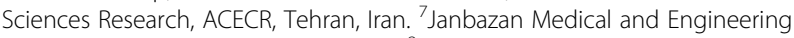
Research Center (JMERC), Tehran, Iran. ${ }^{8}$ Department of Biostatistics, Fasa University of Medical Sciences, Fasa, Fars Province, Iran. ${ }^{9}$ Department of Psychology, Faculty of Humanity Studies, Tarbiat Modares University, Tehran, Iran. ${ }^{10}$ Department of Immunology, Shahed University, Tehran, Iran.

Received: 22 October 2012 Accepted: 18 April 2013 Published: 24 April 2013

\section{References}

1. Smith KJ, Hurst CG, Moeller RB, Skelton HG, Sidell FR, Sulfur mustard: Its continuing threat as a chemical warfare agent, the cutaneous lesions induced, progress in understanding its mechanisms of action, its long- term health effects and new developments for protection and therapy. J Am Acad Dermatol 1991, 32:765-766.

2. United Nations Security Council: Report of the mission dispatched by the Secretary General to investigate allegations of the use of chemical weapons in the conflict between the Islamic Republic of Iran and Iraq, 1987. New York, USA: United Nations; 1987. Report No.: S/18953.
3. Taghaddosinejad F, Fayyaz AF, Behnoush B: Pulmonary complications of mustard gas exposure: a study on cadavers. Acta Med Iran 2011, 49:233-236.

4. Shohrati M, Davoudi M, Ghanei M, Peyman M, Peyman A: Cutaneous and ocular late complications of sulfur mustard in Iranian veterans. Cutan Ocul Toxicol 2007, 26:73-81.

5. Steinritz D, Emmler J, Hintz M, Worek F, Kreppel H, Szinicz L, Kehe K: Apoptosis in sulfur mustard treated A549 cell cultures. Life Sci 2007, 80:2199-201.

6. WHO: Atlas: mental health resources in the world. Geneva: World Health Organization; 2001.

7. World Federation for Mental Health: World Mental Health Day. The relationship between physical and mental health: Co-occurring disorders. Alexandria: World Federation for Mental Health; 2004

8. Desjarlais R, Eisenberg L, Good B, Kleinman A: World Mental Health problems and priorities in low income countries. New York: Oxford University Press; 1995

9. Khateri S, Ghanei M, Keshavarz S, Soroush M, Haines D: Incidence of lung, eye, and skin lesions as late complications in 34,000 Iranians with wartime exposure to mustard agent. J Occup Environ Med 2003, 45:1136-1143.

10. Hashemian F, Khoshnood K, Desai Mayur M, Falahati F, Kasl S, Southwick S: Anxiety, depression, and posttraumatic stress in Iranian survivors of chemical warfare. JAMA 2006, 296:560-566.

11. Norris FH, Friedman MJ, Watson PJ, Byrne CM, Diaz E, Kaniasty K: 60,000 disaster victims speak: Part I. An empirical review of the empirical literature, 1981-2001. Psychiatry 2002, 65:207-239

12. Vasterling JJ, Schumm J, Proctor SP, Gentry E, King DW, King LA: Posttraumatic stress disorder and health functioning in a non-treatment -seeking sample of Iraq war veterans: a prospective analysis. J Rehabil Res Dev 2008, 45:347-58

13. Vafaee B, Seidy A: Prevalence of depression among physically-disabled veterans in northwestern Iran. IJMS 2004, 29:43-44.

14. Kaplan HI, Sadok BJ: Anxiety disorder. In Synopsis of Psychiatry. Edited by Kaplan HI, Sadok BJ. Baltimore: Kathleen Courtney Millet; 2003:623-632.

15. Constance MP, David MP: Veterans at risk: the health effects of mustard gas and lewisite. Washington, D.C: National Academy Press; 1993.

16. Ghazanfari T, Faghihzadeh $S$, Aragizadeh H, Soroush MR, Yaraee R, Mohammad Hassan Z, Foroutan A, Vaez-Mahdavi MR, Javadi MA, Moaiedmohseni S, Azizi F, Panahi Y, Mostafaie A, Ghasemi H, Shams J, Pourfarzam S, Jalali-Nadoushan MR, Fallahi F, Ebtekar M, Davoudi SM, Ghazanfari Z, Ardestani SK, Shariat-Panahi S, Moin A, Rezaei A, Kariminia A, Ajdary S, Mahmoudi M, Roshan R, Ghaderi S, et al: Sardasht-Iran cohort study of chemical warfare victims: design and methods. Arch Iran Med 2009, 12:5-14

17. Derogatis LR, Melisaratos N: The brief symptom inventory: an introductory report. Psychol Med 1983, 13:595-605.

18. Derogatis LR: Symptom checklist-90-revised (SCL-90-R). In Handbook of psychiatric measures. Washington, DC: American Psychiatric Association; 2000:81-84.

19. Bagheri Yazdi SA, Bolhari J, Shahmohammadi D: Psychiatric disorders in the rural district of Meybod (Yazd, Iran). Q J Andisheh Raftar 1994, 1:32-41. Article in Persian.

20. Mirzaee R: Evaluation of the reliability and validity of SCL-90 test in Iran. Iran: Faculty of Literature and Humanities Sciences, Tehran University; 1980 [thesis for MSc degree].

21. Ghaedi G, Ghasemi H, Mousavi B, Soroush MR, Rahnama R, Jafari F, Afshin-Majd S, Sadeghi Naeeni M: Impact of psychological problems in chemical warfare survivors with severe ophthalmologic complication, a cross sectional study. Health Qual Life Outcomes 2012, 10:36

22. Ishoy T, Knop J, Suadicani P, Guldager B, Appleyard M, Gyntelberg F: Increased psychological distress among Danish gulf War veteranswithout evidence for a neurotoxic background. The Danish gulf War study. Dan Med Bull 2004, 51:108-113.

23. Jankovic S, Stivicevic V, Dodig G, Biocic M, Stajner I, Primorac D: Psychological characteristics of wounded and disabled Croatian war veterans. Mil Med 1998, 163:331-336. 
24. McCauley LA, Lasarev M, Sticker D, Rischitelli DG, Spencer PS: Illness experience of Gulf War veterans possibly exposed to chemical warfare agents. Am J Prev Med 2002, 23:200-206.

25. Riddle JR, Brown M, Smith T, Ritchie EC, Brix KA, Romano J: Chemical warfare and the Gulf War: a review of the impact on Gulf veterans' health. Mil Med 2003, 168:606-613.

26. Razavi SM, Salamati P, Saghafinia M, Abdollahi M: A review on delayed toxic effects of sulfur mustard in Iranian veterans. Daru 2012, 20:51.

27. Balali-Mood M, Hefazi M: Comparison of early and late toxic effects of sulfur mustard in Iranian veterans. Basic Clin Pharmacol Toxicol 2006 99:273-82.

doi:10.1186/1477-7525-11-69

Cite this article as: Roshan et al: Long-term effects of sulfur mustard on civilians' mental health 20 years after exposure (The Sardasht-Iran Cohort Study). Health and Quality of Life Outcomes 2013 11:69.

\section{Submit your next manuscript to BioMed Central and take full advantage of:}

- Convenient online submission

- Thorough peer review

- No space constraints or color figure charges

- Immediate publication on acceptance

- Inclusion in PubMed, CAS, Scopus and Google Scholar

- Research which is freely available for redistribution 